teaching. On top of this, individuals have to fit in a healthy work-life balance.

During training, I decided that sectorised jobs involved too many competing demands. I opted to work only with in-patients as a part-time consultant. Unfortunately, many trusts that I approached for jobs struggled to accommodate this style of working

I have been able to take advantage of an opportunity offered by National Health Service professionals. I started in February on the New Consultant Entry Scheme, which offers a 6 month trial with support, mentoring and extra continuing professional development time. There have been teething problems but the chance to try out newer ways of working on a trial basis seemed less risky than committing to a substantive job only to walk away.

Afshan Khawaja Consultant Psychiatrist North Manchester General Hospital, Delaunays Road, Crumpsall, Manchester M8 5RB

\section{Melatonin use in children}

Armour \& Patton write a helpful review on the use of Melatonin in children (Psychiatric Bulletin, June 2004, 28, 222-224). Several studies they mentioned were with blind subjects. It is important to consider that blind people have free-running circadian rhythms that are not amenable to the most powerful of resetting cues - light. The use of melatonin to trigger the new 24-hour period is very powerful in this population (Sack et al, 2000).

Lewy et al (2002) showed that low levels of melatonin, $0.5 \mathrm{mg}$, reset rhythm but not high doses, $2 \mathrm{mg}$. The prolonged half-life of melatonin and the sensitivity of the circadian rhythm to its presence mean that in trying to achieve phase advancement (bringing sleep forward to combat 'sundowning' in the elderly) or delay (delaying sleep onset to combat 'jetlag') melatonin has a window effect. Too low a dose and no effect, too high and the chronobiologic effects are lost and the direct somnolent action is experienced. It would be a shame if a potentially useful treatment for circadian rhythm disorders, including sleep disturbances and seasonal affective disorders, were discarded prematurely due to a perceived lack of efficacy.

\section{Declaration of interest}

The author uses melatonin to reduce recovery time from intercontinental jetlag: personal use only.

LEWY, A. J., EMENS, J. S., SACK, R. L., et al (2002) Low, but not high, doses of melatonin entrained a free-running blind person with long circadian period. Chronobiology International, 19, 649-658.
SACK, R. L., BRANDES, R.W., KENDALL, A. R., et al (2000) Entrainment of free-running circadian rhythms by melatonin in blind people. New England Journal of Medicine 343, 1070-1077.

M. E. J.Wise Consultant Psychiatrist, BECMHT, 13-15 Brondesbury Road, London NW6 6HX. E-mail: ian.wise@nhs.net

\section{Copying letters to patients}

Dr Hughes raises an important issue which would be of concern to most psychiatrists (Psychiatric Bulletin (Correspondence), May 2004, 28, 183). In addition to changing the letters to patients, I wondered if patients opting to receive them belonged, predominantly, to a specific diagnostic group.

I therefore obtained a list of 100 patients who had indicated a choice of whether to receive these letters. The uptake was $76 \%$, which was higher than we expected and their diagnoses were spread out across most diagnostic categories. The majority belonged to the depressive disorder and the neurotic and stress related categories. A higher uptake might have been because other staff members rather than doctors or community psychiatric nurses (associated with poorer uptake) handed out opt-in forms.

A pilot study showed $83 \%$ of patients wanted to continue to receive these letters though $18 \%$ initially found them to be distressing (Harpal Nandhara et al, Psychiatric Bulletin, February 2004, 28 40-42). An appropriate selection of patients to possibly exclude the latter group is thus crucial. Patients who lack capacity and those who present some risk may be considered not suitable to receive these letters (Dale et al, 2003). I now make patients more aware of what is actually written down in their case-notes in the course of the consultation. This hopefully reduces any future surprises when they eventually receive a copy of the letter.

This initiative may alter the relationship between psychiatrists and their patients and thus necessitate a review of this process in future. I will re-survey this group in future to ascertain if their wishes to receive these letters change.

DALE, J., et al (2003) Copying letters to patients. BMJ, $327,450-451$.

Dennis Okolo Specialist Registrar in Psychiatry Ashcombe Centre, Cheddleton, Staffordshire ST13 7ED

\section{Cannabis reclassification}

On 29 January 2004, cannabis was reclassified using the groupings of the
Misuse of Drugs Act 1971 from Class B to Class $C$. As well as the increasing evidence that the drug is harmful to both physical and mental health, which has been recently highlighted (Henry et al, 2003; Rey \& Tennent, 2002) this has caused confusion and concern regarding its legal position. This has been highlighted in articles on TV, broadsheet ('Cloud of confusion over cannabis', Daily Telegraph, 23 January 2004) and tabloid newspapers ('Pot a joke', The Sun, 23 January 2004).

We would like to report our deep concern that this confusion may extend to the medical student population, 5 days after the reclassification.

As part of an evaluation of a substance misuse lecture given to first year medical students at Sheffield University, 163 completed an evaluation form (62\% response rate) (fig. 1). When asked if smoking cannabis at home by yourself was illegal, $42 \%$ of the responders answered incorrectly that it was not. Eighteen per cent were under the misapprehension that smoking cannabis in a public place was not an arrestable offence. Surprisingly, given the publicity, $41 \%$ did not know the drug class cannabis resin belonged to.

Further questions in the evaluation related to other drugs, their purchase and means of administration. We highlight these findings because cannabis is known to be the most widely used illegal drug among medical students (Pickard et al, 2000 ), with reports of $54 \%$ of males and $40 \%$ of females using at least once (Webb et al, 1998).

If this surprising level of ignorance exists in medical students, we wonder what the understanding of the rest of the population is. This is especially important given that those of a similar age to our students are most likely to use cannabis, the government's own data showing that $44 \%$ of $16-29$ year-olds have used the drug (Home Office, 2000).

HOME OFFICE (2000) British Crime Survey 2000, Research, Development and Statistics Directorate. www.homeoffice.gov.uk/rds/pdfs/hcrs224.pdf.

HENRY, J. A., OLDFIELD, W. L. G. \& KON, O. M. (2003) Comparing cannabis with tobacco. BMJ, 326, 942-943.

PICKARD, M., et al (2000) Alcohol and drug use in second-year medical students at the University of Leeds. Medical Education, 34, $148-150$.

REY, J. M. \& TENNENT, C. C. (2002) Cannabis and mental health. BMJ, 325, 1183-1184.

WEBB, E., et al (1998) An update on British medical students' lifestyles. Medical Education, 32. $325-331$.

R. Verity SpR in Psychiatry, Rotherham Community DrugTeam, Medway House, 1-3 Chatham Street, Rotherham S65 1DP 